\title{
Bronchial asthma in a paediatric nurse caused by inhaled pancreatic extracts
}

\section{J P Hayes, A J Newman Taylor}

We report a case of rhinitis and asthma in a paediatric auxillary nurse caused by allergy to powdered pancreatic extract to which she was exposed in her work.

\section{Case report}

A 53 year old female paediatric auxiliary nurse who had worked in the same unit for seven years presented with a three year history of nasal discharge, shortness of breath, wheeze, and chest tightness. She had noticed that her symptoms usually developed about 30 minutes after mixing powdered pancreatic extract with feeds for infants with cystic fibrosis and usually only resolved after two to three days of avoiding exposure to the pancreatic extract. She stopped mixing the pancreatic powder with infant feeds, but continued to work on the same ward and her symptoms persisted. She or her family had no history of eczema or asthma, but she had had hay fever for 20 years. About 18 months before her referral she was prescribed atenolol for mild hypertension. This provoked an episode of wheeze and was therefore discontinued. She was a non-smoker.

At the time of presentation her forced expiratory volume in one second $\left(\mathrm{FEV}_{1}\right)$ and forced vital capacity (FVC) were 1.681 and 2.681 before and 1.921 and 2.551 after inhalation of bronchodilator. She had immediate skin prick test reactions provoked by extracts of grass pollen, cat and dog hair, house dust mite (Bencard), and an extract of Pancrex $\mathrm{V}$ $(1 \mathrm{mg} / \mathrm{ml})$. Specific IgE (expressed as radioallergosorbent test (RAST) binding) for Pancrex V was $50 \%$ (control sera $<2 \%$ ). Her eosinophil count was $180 \times 10^{-3} \mathrm{ml}$. Serial peak readings recorded every two hours for four weeks showed asthma, but no clear relation to periods at work.

She was admitted for inhalation testing with pancreatic extract. Her $\mathrm{FEV}_{1}$ did not vary by more than $10 \%$ during the day after exposure to lactose alone. After exposure to Pancrex $\mathrm{V}$ powder she developed running of her nose and eyes and a dual asthmatic response (figure), which was reproduced

Department of Occupational and Environmental Medicine, National Heart and Lung Institute, Royal Brompton and National Heart Hospital, Dovehouse St, London SW3 6LR, UK

J P Hayes, A J Newman Taylor

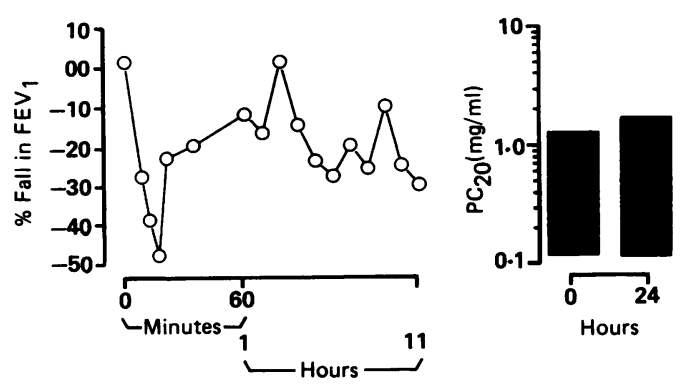

Inhalation test to $0.01 \%$ Pancrex powder in $250 \mathrm{mg}$ lactose. Per cent fall in FEV, and histamine $P C_{20}$ before and 24 hours after the inhalation test are shown.

by the same test on a separate day. No appreciable change in bronchial reactivity occurred on the control or test days. Her histamine $\mathrm{PC}_{20}$ before exposure to Pancrex $\mathrm{V}$ was $1.18 \mathrm{mg} / \mathrm{ml}$ and $1.5 \mathrm{mg} / \mathrm{ml} 24$ hours later. The patient was advised to avoid further exposure to pancreatic extracts by working on a ward without children with cystic fibrosis. Two months after avoiding exposure to such extracts, her symptoms were improved. She continues to take inhaled Becloforte and Ventolin.

\section{Discussion}

Pancrex $\mathrm{V}$ is a porcine pancreatic extract containing free protease, lipase, and amylase. It is prescribed for patients with fibrocystic disease of the pancreas or chronic pancreatitis, and after pancreatectomy. It is made up as a powder and in capsules, tablets, and granules. The powder, which is mixed with milk for infant feeds, is light, easily dispersed in air, and inhalable. Bronchial asthma and rhinitis due to inhaled pancreatic extracts have been reported in pharmaceutical workers ${ }^{1}$ and in the parents of children with cystic fibrosis. ${ }^{23}$ Although not previously described, it is a potential hazard to health workers who prepare feeds for infants requiring pancreatic replacement. This paediatric nurse has unequivocal evidence of asthma caused by pancreatic extract inhaled at work: she gave a history of work related respiratory symptoms, specific IgE to Pancrex V (identified by skin test and RAST), and a dual asthmatic response reproducibly provoked by inhalation testing with Pancrex V powder. Health workers should avoid exposure to pancreatic extracts 
in powder form and granules or capsules should be used as an alternative where possible.

Requests for reprints to: A J Newman Taylor, Department of Occupational and Environmental Medicine, Royal Brompton and National Heart Hospital, Dovehouse St, London SW3 6LR.
1 Nakamura S. Studies on asthma bronchiale. An occupational allergy caused by pancreatin in pharmacists. Japanese Journal of Allergy 1971;20:361-4.

2 Dolan TF, Meyers A. Bronchial asthma and allergic rhinitis associated with inhalation of pancreatic extracts. Am Rev Respir Dis 1974;110:812-3.

3 Sakula A. Bronchial asthma due to allergy to pancreatic extract: a hazard in the treatment of cystic fibrosis. Br J Dis Chest 1977; 71:295-9.

Accepted 29 October 1990 